\title{
Evaluation of Symptoms of Temporomandibular Disorders in Orthodontic Appliance Users
}

\author{
Evaluación de los Síntomas de Trastornos Temporomandibulares \\ en los Usuarios de Aparatos Ortodónicos
}

\begin{abstract}
Paulo Victor da Silva Araújo'; Wilson Moreira Saraiva1; Natã Cavalcante Pereira1; Raquel Gonçalves Vieira-Andrade ${ }^{2}$; Carolina Carvalho de Oliveira Santos ${ }^{3}$ \& Thiago Fonseca-Silva ${ }^{4}$
\end{abstract}

\begin{abstract}
ARAÚJO, P. V. S.; SARAIVA, W. M.; PEREIRA, N. C.; VIEIRA-ANDRADE, R. G.; SANTOS, C. C. O. \& FONSECA-SILVA, T. Evaluation of symptoms of temporomandibular disorders in orthodontic appliance users. Int. J. Odontostomat., 12(1):99104, 2018.

ABSTRACT: Temporomandibular joint disorders (TMD) are multifactorial pathological conditions that can generate significant impacts on quality of life of individuals. Orthodontics treatments have been discussed in the current literature due to its possible association with the development of TMD. The aim of this study was to evaluate the relationship between the use of fixed orthodontic appliances and the symptoms of TMD. This cross-sectional study was performed with a sample of 336 undergraduate dental students that answered a structured questionnaire about symptoms of TMD. The sample was paired for sex and use of fixed orthodontic appliances. The results highlighted that the most prevalent symptoms of TMD were headaches $(21.4 \%, \mathrm{n}=72)$, temporomandibular joint noises $(21.4 \%, \mathrm{n}=72)$ and head and/or neck pain $(20.0 \%$, $\mathrm{n}=67)$. The most of sample, $60.4 \%(n=203)$, showed mild TMD symptomatology. No statistical association was observed between the use of orthodontic appliances and TMD symptoms $(p=0.121)$. It can be suggested that the use of fixed orthodontic appliances is not a factor associated with the symptoms of TMD. Still, it is possible to conclude that the prevalence of light TMD symptoms in dentistry students is high.
\end{abstract}

KEY WORDS: occlusion, temporomandibular joint, orthodontics.

\section{INTRODUCTION}

Temporomandibular disorder (TMD) is a collective term that described a heterogeneous group of conditions that involve the masticatory musculature, the temporomandibular joint (TMJ) and associated structures (Dimitroulis, 1998; Shaffer et al., 2014). Its most common features are regional pain in the face, limitations in jaw movements and noises from the TMJs during jaw movements (Schiffman et al., 2014; Manfredini \& Poggio, 2016; List \& Jensen, 2017 ). It can also be manifested through articular noises, difficulties in chewing and cutting food, headaches and pain in the TMJ region, ear fullness, earache, tinnitus, dizziness and articular disc displacements (Conti et al., 2007; List \& Jensen).
The etiology and pathogenesis of TMD are still unclear. This disorder seems to have a multifactorial cause with interaction of psychological, genetic, neurological and anatomic factors (Chisnoiu et al., 2015; Manfredini \& Poggio). Factors such as depression, stress and anxiety seem to be directly involved into the development and progression of TMD (Rollman \& Gillespie, 2000; Licini et al., 2009). Anatomical factors such as occlusal disharmony, when associated to psychological findings, can release tensions through the stomatognathic system potentiating the symptoms of pain and joint disorders (Rugh \& Solberg, 1976; List \& Jensen).

\footnotetext{
${ }^{1}$ School of Dentistry; Centro Universitário Doutor Leão Sampaio - UNILEÃO; Juazeiro do Norte, Ceará, Brazil.

2 Department of Pediatric Dentistry; School of Dentistry; Universidade Federal de Minas Gerais - UFMG; Belo Horizonte, Minas Gerais, Brazil. ${ }^{3}$ Department of Restorative Dentistry; School of Dentistry; Universidade Federal do Paraná - UFPR; Curitiba, Paraná, Brazil.

${ }^{4}$ Department of Dentistry; Division of Orthodontics; School of Biological and Health Sciences, Universidade Federal dos Vales do Jequitinhonha e Mucuri - UFVJM; Diamantina, Minas Gerais, Brazil.
} 
Orthodontic treatments have been extensively discussed in the current literature due to its possible association with the development of TMD. The literature suggests the imbalances in the dental occlusion in primary or permanent dentitions may be factors linked to TMD (Bourzgui et al., 2010; Fernández-González et al., 2015). The actions of orthodontic treatments on TMD have not already been completely elucidated. The aim of the current study was to evaluate the relationship between the use of fixed orthodontic appliances and symptoms of temporomandibular disorders.

\section{MATERIAL AND METHOD}

This cross-sectional study was performed with sample of 336 undergraduate dental students at School of Dentistry of the northeastern region of Brazil. All of the individuals answered a structured questionnaire about the use of fixed orthodontic appliances and TMD symptoms. To compose this study, individuals of different sex and over age 18 years old were selected. The sample was paired for sex and use of complete fixed orthodontic appliances in maxillary and mandibular teeth. This study was approved by the research ethics committee (Protocol No 1.430.327).

The questionnaire used for the current work was previously described (Conti et al., 1996, 2003). This instrument is composed of 10 objective questions related to TMD symptoms that approach questions linked to emotional tensions, parafunctional habits consciousness and articular symptomatology. Three types of answers where available for questions about TMJ: "yes", "no" or "sometimes". For determining the presence and degree of TMD, values "0", " 1 " and "2" were attributed to the answers of the questionnaire. For each answer indicating the presence of TMD, a value of " 2 " was given. The value " 0 " indicated the absence of symptoms. The value "1" was given when occasional occurrence of TMD symptoms was reported. The sum of the values was used for classifying the samples in three categories: Absence of TMD for values ranged from 0 to 3; mild TMD from 4 to 8; moderate/severe TMD from 9 to 20 . Furthermore, questions about sex, age and use of fixed orthodontic appliances were added (Table I).

The data obtained were inserted in software SPSS for Windows version 17.0. The data were performed with frequency, Chi-Square and Fischer Exact tests with a confidence interval of $95 \%(p \leq 0,05)$.

\section{RESULTS}

Table II shows all results of descriptive analysis of the data. From of total of 336 individuals, $50 \%$ $(n=168)$ was female and $50 \%(n=168)$ male, with an average age of 27,60 years (median of 24 years), varying from 18 to 37 years old. About the use or not of orthodontic appliances, $50 \%(n=168)$ of sample reported that they use fixed orthodontic appliances meanwhile $50 \%(n=168)$ reported that they have never used orthodontic appliances.

The results highlighted that the most prevalent symptoms of TMD were the headaches $(21.4 \%, n=72)$, temporomandibular joint noises $(21.4 \%, n=72)$ and head and/or neck pain $(20.0 \%, n=67)$. From the answers given, it was observed that the majority of the sample $(72.6 \%, n=244)$ presented some degree of TMD symptoms. The analysis of TMD symptomatology showed that $60.4 \%$ of sample $(n=203)$ has a mild symptoms and $12.2 \%(n=41)$ showed moderate/ severe.

Table I. Anamnestic questionnaire. Questionnaire

What is your gender?

How old are you?

Do you use orthodontic fixed appliances?

Do you have difficulty to move your mandible from one side to the other?

Do you feel sensitivity or muscular pain when chewing?

Do you frequently feel headache?

Do you feel pain in your neck and/or shoulders?

Do you have difficulty in opening your mouth?

Do you feel pain in the ear region or in the area above your ears (head)?

Do you hear noises or crepitations in the temporomandibular joint when opening or closing the mouth?

Do you consider your bite as normal?

Do you use only one side of your mouth to chew?

Do you feel pain in your face during the morning (when waking up)? 
The analysis of association between the symptoms of TMD (absent, mild, moderate/severe) and the variables of the research were studied. The symptoms of TMD was not associated with the sex of subjects neither to use of orthodontic appliances $(p=0.985$ and $p=0.121$ respectively).

Table II. Descriptive analysis of data.

\begin{tabular}{|c|c|c|}
\hline Evaluated conditions & $\mathrm{n}$ & $\%$ \\
\hline \multicolumn{3}{|l|}{ Sex } \\
\hline Female & 168 & $50.0 \%$ \\
\hline Male & 168 & $50.0 \%$ \\
\hline \multicolumn{3}{|c|}{ Use of orthodontic appliances } \\
\hline Use & 168 & $50.0 \%$ \\
\hline Never & 168 & $50.0 \%$ \\
\hline \multicolumn{3}{|c|}{ Difficulty to move the mandible from one side to the other } \\
\hline Yes & 15 & $4.4 \%$ \\
\hline No & 266 & $79.2 \%$ \\
\hline Sometimes & 55 & $16.4 \%$ \\
\hline \multicolumn{3}{|c|}{ Sensitivity or pain when chewing } \\
\hline Yes & 21 & $6.3 \%$ \\
\hline No & 228 & $67.9 \%$ \\
\hline Sometimes & 87 & $25.9 \%$ \\
\hline \multicolumn{3}{|l|}{ Frequent headaches } \\
\hline Yes & 72 & $21.4 \%$ \\
\hline No & 152 & $45.2 \%$ \\
\hline Sometimes & 112 & $33.3 \%$ \\
\hline \multicolumn{3}{|c|}{ Neck and/or shoulders pain } \\
\hline Yes & 67 & $20.0 \%$ \\
\hline No & 158 & $47.0 \%$ \\
\hline Sometimes & 111 & $33.0 \%$ \\
\hline \multicolumn{3}{|c|}{ Dificulties in opening the mouth } \\
\hline Yes & 11 & $3.3 \%$ \\
\hline No & 263 & $78.3 \%$ \\
\hline Sometimes & 62 & $18.5 \%$ \\
\hline \multicolumn{3}{|c|}{ Pain in the ear region or in the area above the ears (head) } \\
\hline Yes & 20 & $6.0 \%$ \\
\hline No & 265 & $78.9 \%$ \\
\hline Sometimes & 51 & $15.2 \%$ \\
\hline \multicolumn{3}{|c|}{ Noises or crepitations in the temporomandibular joint } \\
\hline Yes & 72 & $21.4 \%$ \\
\hline No & 189 & $56.3 \%$ \\
\hline Sometimes & 75 & $22.3 \%$ \\
\hline \multicolumn{3}{|c|}{ If one considers their bite as normal } \\
\hline Yes & 190 & $56.5 \%$ \\
\hline No & 122 & $36.3 \%$ \\
\hline Sometimes & 24 & $7.0 \%$ \\
\hline \multicolumn{3}{|c|}{ If one uses only one side of the mouth to chew } \\
\hline Yes & 64 & $19.0 \%$ \\
\hline No & 180 & $53.6 \%$ \\
\hline Sometimes & & $27.4 \%$ \\
\hline \multicolumn{3}{|c|}{ Pain in the face when waking up } \\
\hline Yes & 8 & $2.4 \%$ \\
\hline No & 292 & $86.9 \%$ \\
\hline Sometimes & 36 & $10.7 \%$ \\
\hline \multicolumn{3}{|l|}{ TMD symptomatology } \\
\hline Absente & 92 & $27.4 \%$ \\
\hline Mild & 203 & $60.4 \%$ \\
\hline Moderate/severe & 41 & $12.2 \%$ \\
\hline
\end{tabular}




\section{DISCUSSION}

The etiology of TMD is complex and may not be explained on a cause-and-effect basis (Talic, 2011). The results of this study did not show any association between the use of orthodontic appliances and temporomandibular disorders. These findings suggest that the orthodontic treatment with the use of fixed appliances is not an etiological factor related to TMD symptoms. The literature describes that TMD has multifactorial etiology and unpredictable nature, highlighting that malocclusion or use of orthodontic appliances does not configure triggering factors for these disorders (Greene et al., 1999; Conti et al., 2007; Machado et al., 2010).

Several authors describe that orthodontic treatment does not increase the risk for TMD (Sadowsky et al., 1991; Rendell et al., 1992; Egermark et al., 2005; Mohlin et al., 2007). A prospective cohort study performed in South Wales, United Kingdom, investigated the relationship between orthodontic treatments and TMD and concluded that treatments do not cause nor it prevents TMD (Macfarlane et al., 2009). Ruf \& Pancherz (1998) described in their study that the correct orthodontic treatment does not seem to have adverse results in the TMJ in the long term.

Scientific evidences point out that orthodontic treatments do not seem to be linked as an etiologic factor for the beginning, maintenance or evolution of TMD. A study performed at lowa University for evaluating the incidence of TMD symptoms with a sample of 109 subjects post orthodontic treatment concluded that orthodontics was not associated with causes of TMD (Kremenak et al., 1992). The cohort study, followed by Egermark, analyzed patients who had orthodontic care between 1981 and 1983 and followed up of 20 years. The presence of TMD was investigated is all patients. In conclusion, no statistically significant difference was found between the prevalence of TMD in patients who had received orthodontic treatment and those who had not received orthodontic intervention (Egermark et al., 2003, 2005). Another twenty-year cohort study, described by Macfarlane et al., concluded that participants with history of orthodontic treatment did not have higher risk of new or persistent TMD.

These findings suggest that, in general, orthodontic treatment does not provide any further advantages for management or prevention of TMD
(Imai et al., 2000; Henrikson \& Nilner, 2003; FernándezGonzález et al.; Manfredini et al., 2016). In addiction, Luther et al. (2010), in a Cochrane review, points out that there is no evidence that orthodontic treatment can treat or prevent TMD.

Our results showed that the majority of participants of the research presented TMD symptoms. Medeiros et al. (2011) performed a study with a sample of 347 students from the first and the last year of School of Dentistry, Medicine, Pharmacy, Physiotherapy and Nursing. It was verified that most of the individuals, $54.5 \%$, presented a mild TMD, $17.9 \%$ showed moderate TMD and $2.6 \%$ had a severe TMD (Medeiros et al.). These results suggest that TMD may be high prevalence and it's underdiagnosed.

Due to the etiological complexity and physiopathology of TMD their signs and symptoms can appear before, during or after orthodontic treatment (Conti et al., 2003; Henrikson \& Nilner; Conti et al., 2007; Macfarlane et al.; Bourzgui et al.). In this sense, a complete articular diagnosis of patient prior to orthodontic treatment is advisable. Orthodontic treatment should not be started in patients with acute signs and symptoms of TMD (Talic). In cases where the patient shows TMD, the treatment should be postponed until that the disorder be controlled.

\section{CONCLUSION}

It can be suggested that the use of fixed orthodontic appliances is not a factor associated with symptoms of TMDs. Still, it is possible to note that the prevalence of mild TMD symptoms in dentistry students is high.

ARAÚJO, P. V. S.; SARAIVA, W. M.; PEREIRA, N. C.; VIEIRA-ANDRADE, R. G.; SANTOS, C. C. O. \& FONSECASILVA, T. Evaluación de los síntomas de trastornos temporomandibulares en los usuarios de aparatos ortodónicos. Int. J. Odontostomat., 12(1):99-104, 2018.

RESUMEN: Los trastornos de la articulación temporomandibular (TTM) son un grupo de patologías multifactoriales que pueden generar impactos significativos en la calidad de vida de las personas. Los tratamientos de ortodoncia se han discutido en la literatura actual debido a 
su posible asociación con el desarrollo de TTM. El objetivo de este estudio fue evaluar la relación entre el uso de aparatos de ortodoncia fijos y los síntomas de TTM. Se realizó un estudio transversal con una muestra de 336 estudiantes de odontología que respondieron un cuestionario estructurado sobre los síntomas de TTM. La muestra fue emparejada por género y uso de aparatos de ortodoncia fijos. Los resultados destacaron que los síntomas más prevalentes de TTM fueron cefaleas $(21,4 \%, n=72)$, ruidos de la articulación temporomandibular $(21,4 \%, n=72)$ y dolor de cabeza y/o cuello $(20,0 \%, n=67)$. La mayor parte de la muestra, $60,4 \%(n=203)$, presentó síntomas leves de TTM. No se observó asociación estadística entre el uso de aparatos de ortodoncia y los síntomas de TTM $(p=0,121)$. Se puede sugerir que el uso de aparatos de ortodoncia fijos no es un factor asociado con los síntomas de TTM. Aun así, es posible concluir que la prevalencia de síntomas leves de TTM en estudiantes de odontología es alta.

PALABRAS CLAVE: oclusión, articulación temporomandibular, ortodoncia.

\section{REFERENCES}

Bourzgui, F.; Sebbar, M.; Nadour, A. \& Hamza, M. Prevalence of temporomandibular dysfunction in orthodontic treatment. Int. Orthod., 8(4):386-98, 2010

Chisnoiu, A. M.; Picos, A. M.; Popa, S.; Chisnoiu, P. D.; Lascu, L.; Picos, A. \& Chisnoiu, R. Factors involved in the etiology of temporomandibular disorders - a literature review. Clujul Med., 88(4):473-8, 2015

Conti, A. C.; Oltramari, P. V.; Navarro, R. de L. \& de Almeida, M. R. Examination of temporomandibular disorders in the orthodontic patient: a clinical guide. J. Appl. Oral Sci., 15(1):77-82, 2007.

Conti, A.; Freitas, M.; Conti, P.; Henriques, J. \& Janson, G. Relationship between signs and symptoms of temporomandibular disorders and orthodontic treatment: a cross-sectional study. Angle Orthod., 73(4):411-7, 2003.

Conti, P. C.; Ferreira, P. M.; Pegoraro, L. F.; Conti, J. V. \& Salvador, M. C. A cross-sectional study of prevalence and etiology of signs and symptoms of temporomandibular disorders in high school and university students. J. Orofac. Pain, 10(3):254-62, 1996.

Dimitroulis, G. Temporomandibular disorders: a clinical update. BMJ, 317(7152):190-4, 1998

Egermark, I.; Carlsson, G. E. \& Magnusson, T. A prospective longterm study of signs and symptoms of temporomandibular disorders in patients who received orthodontic treatment in childhood. Angle Orthod., 75(4):645-50, 2005.

Egermark, I.; Magnusson, T. \& Carlsson, G. E. A 20-year follow-up of signs and symptoms of temporomandibular disorders and malocclusions in subjects with and without orthodontic treatment in childhood. Angle Orthod., 73(2):109-15, 2003.

Fernández-González, F. J.; Cañigral, A.; López-Caballo, J. L.; Brizuela, A.; Moreno-Hay, I.; Del Río-Highsmith, J. \& Vega, J. A. Influence of orthodontic treatment on temporomandibular disorders. A systematic review. J. Clin. Exp. Dent., 7(2):e3207, 2015.

Greene, C. S.; Mohl, N. D.; McNeill, C.; Clark, G. T. \& Truelove, E. L. Temporomandibular disorders and science: a response to the critics. Am. J. Orthod. Dentofacial Orthop., 116(4):430-1, 1999.

Henrikson, T. \& Nilner, M. Temporomandibular disorders, occlusion and orthodontic treatment. J. Orthod., 30(2):129-37, 2003.

Imai, T.; Okamoto, T.; Kaneko, T.; Umeda, K.; Yamamoto, T. \& Nakamura, S. Long-term follow-up of clinical symptoms in TMD patients who underwent occlusal reconstruction by orthodontic treatment. Eur. J. Orthod., 22(1):61-7, 2000.

Kremenak, C. R.; Kinser, D. D.; Meicher, T. J.; Wright, G. R.; Harrison, S. D.; Ziaja, R. R.; Harman, H. A.; Ordahl, J. N.; Demro, J. G. \& Menard, C. C. Orthodontics as a risk factor for temporomandibular disorders (TMD). II. Am. J. Orthod. Dentofacial Orthop., 101(1):21-7, 1992.

Licini, F.; Nojelli, A.; Segù, M. \& Collesano, V. Role of psychosocial factors in the etiology of temporomandibular disorders: relevance of a biaxial diagnosis. Minerva Stomatol., 58(1112):557-66, 2009.

List, T. \& Jensen, R. H. Temporomandibular disorders: Old ideas and new concepts. Cephalalgia, 37(7):692-704, 2017.

Luther, F.; Layton, S. \& McDonald, F. Orthodontics for treating temporomandibular joint (TMJ) disorders. Cochrane Database Syst. Rev., (7):CD006541, 2010.

Macfarlane, T. V.; Kenealy, P.; Kingdon, H. A.; Mohlin, B. O.; Pilley, J. R.; Richmond, S. \& Shaw, W. C. Twenty-year cohort study of health gain from orthodontic treatment: temporomandibular disorders. Am. J. Orthod. Dentofacial Orthop., 135(6):692e1-8, 2009.

Machado, E.; Machado, P.; Cunali, P. A. \& Grehs, R. A. Orthodontics as risk factor for temporomandibular disorders: a systematic review. Dent. Press J. Orthod., 15(6):e1-10, 2010.

Manfredini, D. \& Poggio, C. E. Prosthodontic planning in patients with temporomandibular disorders and/or bruxism: A systematic review. J. Prosthet. Dent., 117(5):606-13, 2016.

Manfredini, D.; Stellini, E.; Gracco, A.; Lombardo, L.; Nardini, L. G. \& Siciliani, G. Orthodontics is temporomandibular disorder-neutral. Angle Orthod., 86(4):649-54, 2016.

Medeiros, S. P.; Batista, A. U. D. \& Forte, F. D. S. Prevalência de sintomas de disfunção temporomandibular e hábitos parafuncionais em estudantes universitários. RGO, 59(2):2018, 2011.

Mohlin, B.; Axelsson, S.; Paulin, G.; Pietilä, T.; Bondemark, L.; Brattström, V.; Hansen, K. \& Holm, A. K. TMD in relation to malocclusion and orthodontic treatment. Angle Orthod., 77(3):542-8, 2007.

Rendell, J. K.; Norton, L. A. \& Gay, T. Orthodontic treatment and temporomandibular joint disorders. Am. J. Orthod. Dentofacial Orthop., 101(1):84-7, 1992.

Rollman, G. B. \& Gillespie, J. M. The role of psychosocial factors in temporomandibular disorders. Curr. Rev. Pain, 4(1):71-81, 2000.

Ruf, S. \& Pancherz, H. Long-term TMJ effects of Herbst treatment: a clinical and MRI study. Am. J. Orthod. Dentofacial Orthop., 114(5):475-83, 1998

Rugh, J. D. \& Solberg, W. K. Psychological implications in temporomandibular pain and dysfunction. Oral Sci. Rev., 7:330, 1976.

Sadowsky, C.; Theisen, T. A. \& Sakols, E. I. Orthodontic treatment and temporomandibular joint sounds--a longitudinal study. Am. J. Orthod. Dentofacial Orthop., 99(5):441-7, 1991.

Schiffman, E.; Ohrbach, R.; Truelove, E.; Look, J.; Anderson, G.; Goulet, J. P.; List, T.; Svensson, P.; Gonzalez, Y.; Lobbezoo, F.; Michelotti, A.; Brooks, S. L.; Ceusters, W.; Drangsholt, M.; Ettlin, D.; Gaul, C.; Goldberg, L. J.; Haythornthwaite, J. A.; Hollender, L.; Jensen, R.; John, M. T.; De Laat, A.; de Leeuw, R.; Maixner, W.; van der Meulen, M.; Murray, G. M.; Nixdorf, D. R.; Palla, S.; Petersson, A.; Pionchon, P.; Smith, B.; Visscher, C. M.; 
ARAÚJO, P. V. S.; SARAIVA, W. M.; PEREIRA, N. C.; VIEIRA-ANDRADE, R. G.; SANTOS, C. C. O. \& FONSECA-SILVA, T. Evaluation of symptoms of temporomandibular disorders in orthodontic appliance users. Int. J. Odontostomat., 12(1):99-104, 2018.

Zakrzewska, J.; Dworkin, S. F.; International RDC/TMD Consortium Network; International association for Dental Research; Orofacial Pain Special Interest Group \& International Association for the Study of Pain. Diagnostic Criteria for Temporomandibular Disorders (DC/TMD) for Clinical and Research Applications: recommendations of the International RDC/TMD Consortium Network* and Orofacial Pain Special Interest Groupt. J. Oral Facial Pain Headache, 28(1):6-27, 2014.

Shaffer, S. M.; Brismée, J. M.; Sizer, P. S. \& Courtney, C. A. Temporomandibular disorders. Part 1: anatomy and examination/ diagnosis. J. Man. Manip. Ther., 22(1):2-12, 2014.

Talic, N. F. Adverse effects of orthodontic treatment: A clinical perspective. Saudi Dent. J., 23(2):55-9, 2011.
Corresponding author:

Prof. Dr. Thiago Fonseca-Silva

Department of Dentistry; Division of Orthodontics

Universidade Federal dos Vales do Jequitinhonha e Muciri - UFVJM

Rua da Glória, 187 - Diamantina

Minas Gerais

BRAZIL

E-mail: thiagofonsecasilva@gmail.com

Received: 25-11-2017

Accepted: 23-12-2017 